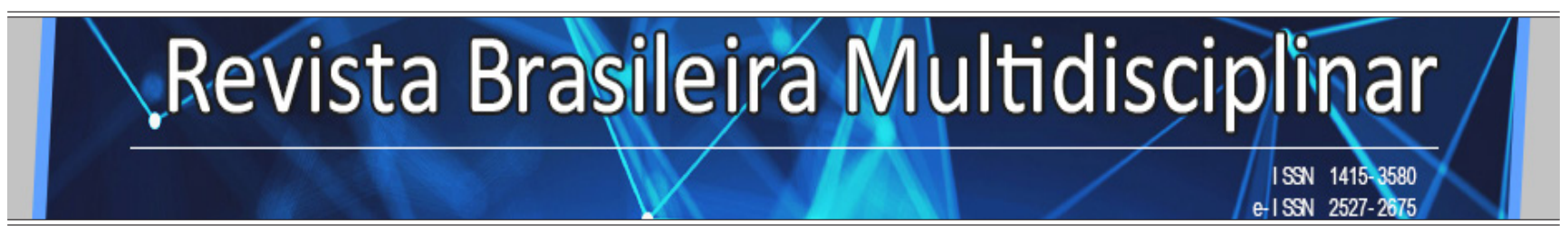

http://revistarebram.com/index.php/revistauniara

\title{
ANÁLISE DA RESISTÊNCIA À COMPRESSÃo UNIAXIAL DE COMPÓSITOS CIMENTÍCIOS COM BAGAÇO E CINZAS DA CANA-DE-AÇÚCAR
}

\author{
Marcela Margarida Soares Amaral ${ }^{\star}$; Matheus da Silva Lages**. \\ ${ }^{*}$ Bacharelanda em Ciência e Tecnologia - Universidade Federal dos Vales do Jequitinhonha e Mucuri. \\ ${ }^{*}$ Mestrado em Engenharia Mecânica - Universidade Federal dos Vales do Jequitinhonha e Mucuri \\ *Autor para correspondência e-mail: matheuslages@yahoo.com.br
}

\section{Palavras-chave}

Compósito Cimentício

Fibras de Bagaço De Cana-De-Açúcar

Resistência À Compressão

\section{KEYWORDS}

Cement Composite

Sugarcane Bagasse Fibers

Compressive Strength

\section{RESUMO}

Atualmente, a cana-de-açúcar é o produto mais produzido e exportado no Brasil, gerando uma grande quantidade de resíduos após o aproveitamento dos produtos. Este estudo tem como objetivo avaliar a adição de fibras do bagaço de cana-de-açúcar em compósitos cimentícios. Os corpos de prova foram submetidos a ensaios de compressão uniaxial para verificar a resistência, onde foi constatado que as fibras consideradas finas apresentaram aumento de resistência à compressão devido ao acréscimo da fração mássica e as fibras consideradas grossas apresentaram diminuição com o acréscimo da fração mássica no compósito cimentício. Após o ensaio observou-se que a resistência à compressão dos materiais que apresentavam fibras de bagaço de cana-de-açúcar foi inferior ao material sem fibras, contudo, o uso das fibras pode ser levado em consideração para algumas aplicações que não necessitam de grandes valores de resistência, gerando benefícios como redução da densidade do material e diminuição no uso de cimento.

\begin{abstract}
ANALYSIS OF THE UNIAXIAL COMPRESSIVE STRENGTH OF CEMENTITIOUS COMPOSITES WITH BAGASSE AND ASH FROM SUGARCANET

Currently, sugarcane is the most produced and exported product in Brazil, generating a large amount of waste after the use of the products. This study aims to evaluate the addition of sugarcane bagasse fibers to cement composites. The test specimens were subjected to uniaxial compression tests to verify the resistance, where it was found that the fibers considered thin had an increase in compressive strength due to the increase of the mass fraction and the fibers considered as coarse showed decrease with the increase of the mass fraction in the cementitious composite. After the test it was observed that the compressive strength of materials containing sugarcane bagasse fibers was lower than the material without fibers, however, the use of the fibers can be taken into account for some applications that do not require large values of resistance, generating benefits such as reduction of the material density and decrease in the use of cement.
\end{abstract}




\section{INTRODUÇÃo}

A agroindústria brasileira de cana-de-açúcar objetiva a produção de açúcar como recurso para o abastecimento dos mercados interno e externo e também a produção do álcool combustível para atendimento da demanda nacional de combustíveis. Segundo dados do CONAB (2018) um levantamento realizado na safra de 2018/2019, o Brasil teve uma produção de cerca de 625,96 milhões de toneladas de cana-de-açúcar tornando-se assim o maior produtor e exportador mundial da mesma. A execução do projeto PROALCOOL (Programa Nacional do Álcool) no Brasil impulsionou a indústria sucroalcooleira, o que resultou num aumento considerável da geração de resíduos (ZARDO et al., 2014). A cultura da cana no país foi introduzida sem a devida preocupação com o aproveitamento comercial dos subprodutos. Os principais subprodutos das usinas de açúcar e álcool são o vinhoto, a torta de filtro e o bagaço.

Atualmente existe a necessidade global de desenvolvimento sustentável visando a sobrevivência das gerações futuras, sendo que o setor da construção civil tem papel fundamental para a realização do mesmo, uma vez que a construção civil é altamente dependente dos recursos do meio ambiente. Com a preocupação crescente na preservação do no meio ambiente, empresas vêm buscando alternativas para a substituição dos agregados naturais utilizados na construção civil pela incorporação de resíduos na confecção de argamassas e concretos (MACEDO, 2009). Além da busca por alternativas sustentáveis, é viável e interessante encontrar no setor da construção civil soluções que reduzam o peso da construção sem perder a segurança do mesmo, pois, quanto menor o peso de algumas partes da construção menor a necessidade de elementos e projetos mais robustos.

De acordo com Lima (2014) e Helene \& Andrade (2010) o material mais utilizado na construção civil é o concreto, que é um material compósito. Os compósitos são materiais originados por uma combinação criteriosa de dois ou mais elementos, mas na sua maioria é composta por duas fases: a matriz que é contínua e envolve a outra fase conhecida como fase dispersa, sendo que as propriedades dos compósitos são dependentes das propriedades de cada uma de suas fases, quantidades relativas e da geometria da fase dispersa, sendo esta última, caracterizada pelo formato, tamanho, distribuição e orientação de suas partículas (CALLISTER, 2008). O concreto é composto por uma mistura de cimento, agregados graúdos (pedras), agregados miúdos (areia), água, aditivos e adições (sílica ativa), sendo que o produto da mistura resulta em um material com ótima resistência à compressão e de fácil modelagem, possibilitando seu uso em grande escala na construção civil.

Diversos estudos são realizados com resíduos dos processos que envolvem a cana de açúcar, como por exemplo, a utilização das fibras de cana de açúcar como subprodutos em compósitos cimentícios. A adição de fibras com granulometria variando entre 7-20 e 20-35 US-Tyler em diferentes concentrações pode reduzir a resistência mecânica do compósito cimentício, entretanto o seu uso pode ser viabilizado em algumas construções simples, que não exigem valores extremos de resistência (VIEIRA et al., 2016). Este trabalho busca avaliar a resistência à compressão do compósito cimentício, substituindo parte do cimento por fibras de diferentes granulometrias e cinzas da cana-de-açúcar.

\section{MATERIAIS E MÉtodos}

Os experimentos foram planejados de forma a obter os fatores e níveis experimentais específicos para serem analisados, sendo eles: adição mássica de fibras (0,5\%, 1\%, 2\%) e granulometria US-Tyler 7-20 (denominada grossa) e US-Tyler 40-35 (denominada fina). A Tabela 1 apresenta as condições experimentais investigadas contendo fibras de bagaço da cana-de-açúcar. A condição experimental 7, que possui apenas cinzas como fase dispersa no compósito, foi necessária para servir como referência para as outras condições experimentais. Foram fabricados 10 corpos de prova para cada uma das condições 
experimentais no laboratório de Mecânica dos Fluidos da Universidade Federal dos Vales do Jequitinhonha e Mucuri, campus Mucuri, em Teófilo Otoni - MG. A proporção dos materiais utilizados para confecção é apresentada na Tabela 2.

Os bagaços de cana foram obtidos em um quiosque na cidade de Teófilo Otoni-MG. Onde foram limpos em água corrente e secos posteriormente. Após a secagem houve a trituração dos mesmos e peneiramento (Figura 1), diferenciando assim as fibras grossas das fibras finas.

Tabela 1- Condições Experimentais.

\begin{tabular}{cccc}
\hline $\begin{array}{c}\text { Condições } \\
\text { experimentais }\end{array}$ & Adição de fibras (\%) & Granulometria & $\begin{array}{c}\text { Estado das } \\
\text { fibras }\end{array}$ \\
\hline $\mathbf{1}$ & 0,5 & Grossa & Tratada \\
$\mathbf{2}$ & 1 & Grossa & Tratada \\
$\mathbf{3}$ & 2 & Grossa & Tratada \\
$\mathbf{4}$ & 0,5 & Fina & Tratada \\
$\mathbf{5}$ & 1 & Fina & Tratada \\
$\mathbf{6}$ & 2 & Fina & Tratada \\
$\mathbf{7}$ & 0 & Cimento e Cinza & - \\
\hline \multicolumn{4}{c}{ Fonte: Elaboração Própria. }
\end{tabular}

Tabela 2 - Materiais Utilizados.

\begin{tabular}{ccc}
\hline \hline Materiais & Porcentagem (\%) & Massa (g) \\
\hline Cimento & 95 & 2850 \\
Cinza & 5 & 150 \\
Fibra & $0,5 / 1,0 / 2,0$ & $15 / 30 / 60$ \\
Água & & 1425 \\
\hline
\end{tabular}

Fonte: Elaboração Própria.

Figura 1 - Bagaço de cana:(A) Triturado; (B) Peneirado.

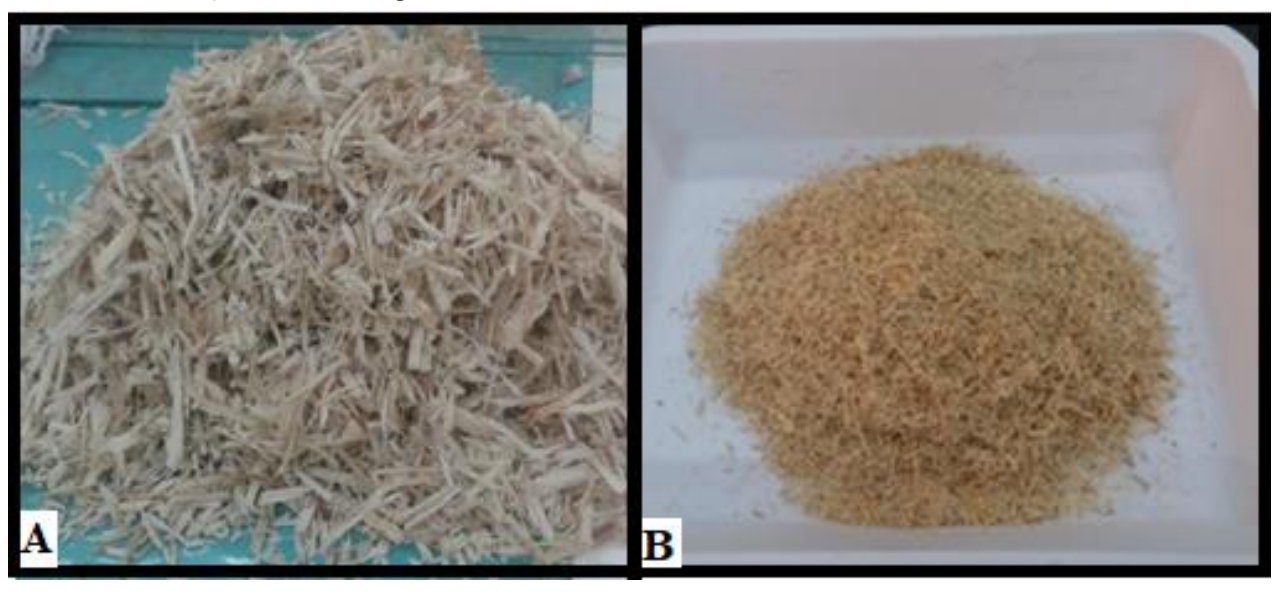

Fonte: Elaboração Própria. 
Para ocorrer a inserção das fibras na pasta cimentícia foi necessário fazer o processo de merceirização (Figura 2-A), realizado em solução com 10\% em massa de hidróxido de sódio ( $\mathrm{NaOH})$. Após o tratamento químico as fibras foram lavadas sucessivas vezes até atingir o $\mathrm{pH}$ neutro (Figura 2-B). Utilizaram-se faixas granulométricas de abertura US-Tyler 7-20 e US-Tyler 40-35 através do peneiramento manual.

A fabricação das amostras foi conduzida misturando manualmente a matriz e as fases dispersas nas proporções e condições pré-determinadas, como mostrado na Figura 3 - A. Para a confecção dos corpos de prova foram utilizados moldes cilíndricos metálicos com $25 \mathrm{~mm}$ de diâmetro e $100 \mathrm{~mm}$ de altura (Figura 3 - B), seguindo a recomendação da NBR 5738 (ABNT, 2015). A moldagem dos corpos de prova foi feita imediatamente após a confecção com o auxílio de uma espátula em quatro camadas de alturas aproximadamente iguais, recebendo cada camada 15 golpes, homogeneamente distribuídos, com um soquete feito de material não corrosivo (Figura 3 - C). Os corpos de prova passaram pelo processo de cura úmida por 28 dias (Figura 3 - D), sendo posteriormente submetidos a ensaios de compressão, realizados de acordo com recomendações da NBR 7215 (ABNT, 1997).

Os ensaios de compressão (Figura 4 -A) foram realizados de acordo com a NBR 5739 (ABNT, 1994). Para o ensaio, utilizou-se uma prensa hidráulica elétrica digital, modelo CI, da marca SOLOCAP, que possui uma carga máxima de $1000 \mathrm{kN}$ (Figura 4 -B).

Figura 2 - Tratamento das fibras:(A) Processo de merceirização; (B ) Fibras lavadas.

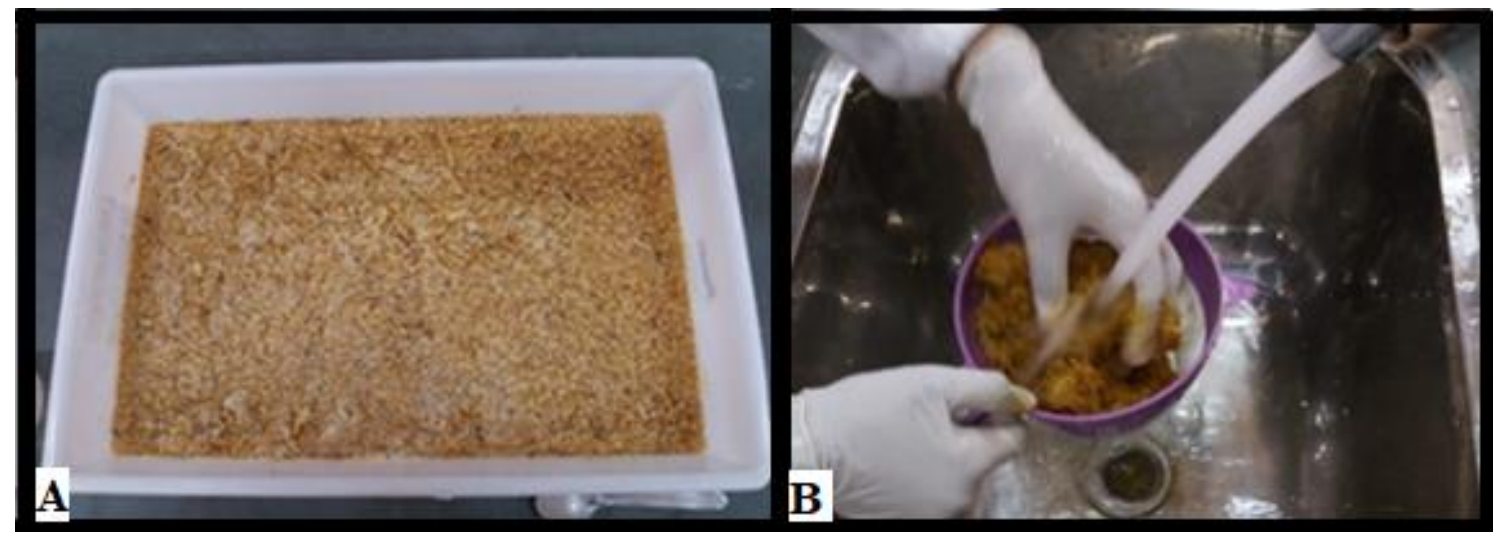

Fonte: Elaboração Própria. 
AMARAL et. al

Figura 3 - Fabricação Corpo de Prova: (A) Mistura da fase matriz e fases dispersas; (B) Moldagem corpo de prova; (C) Molde cilíndrico; (D) Fase de cura.

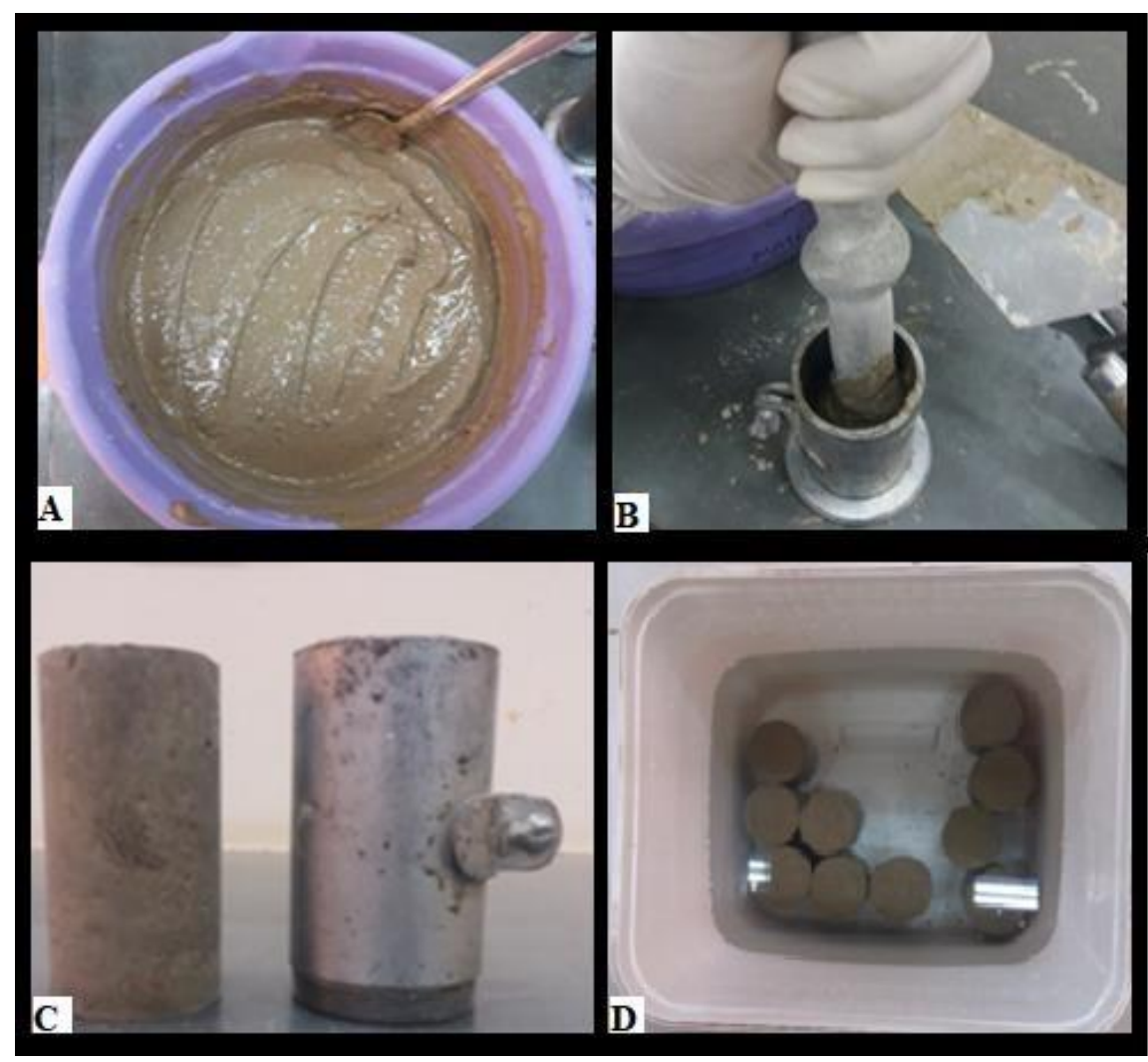

Fonte: Elaboração Própria.

Figura 4 - Ensaio de compressão: (A) Ensaio corpo de prova; (B) Prensa hidráulica SOLOCAP.

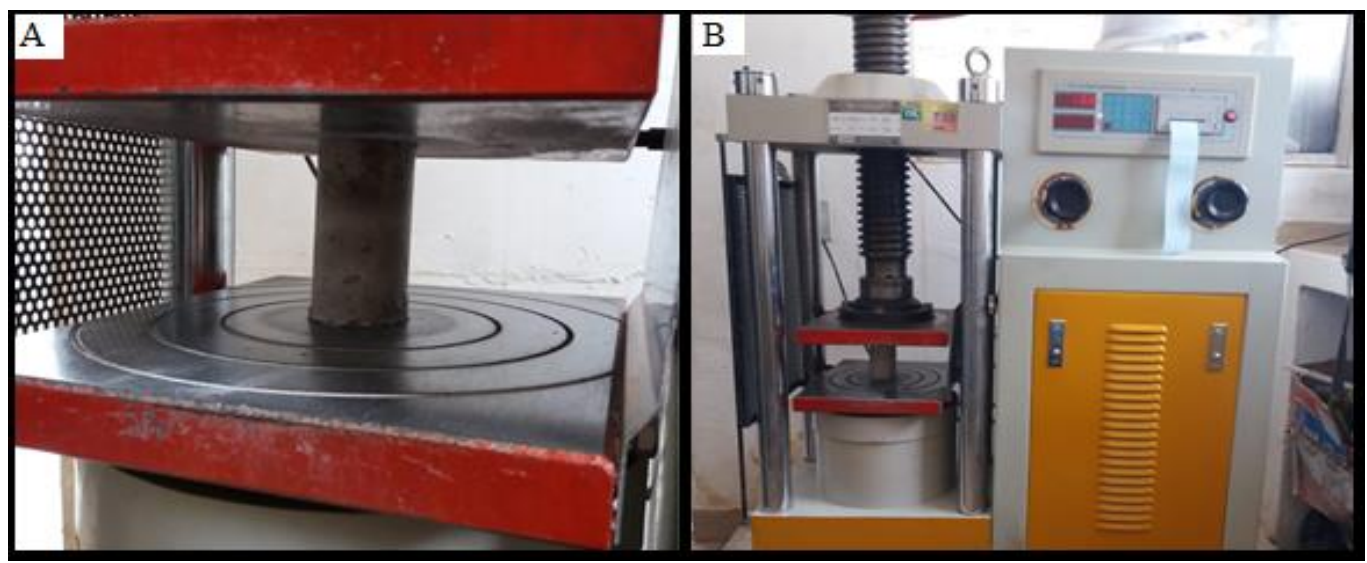

Fonte: Elaboração Própria.

\section{Resultados E discussões}

A Tabela 3 apresenta os resultados médios obtidos dos ensaios de compressão para cada condição experimental. Uma comparação entre os valores médio obtidos para as fibras consideradas finas e grossas, em suas devidas proporções, é apresentado no Gráfico 1. 
Tabela 3 - Média dos resultados dos ensaios de compressão.

\begin{tabular}{cc}
\hline $\begin{array}{c}\text { Condições } \\
\text { experimental }\end{array}$ & Compressão (MPa) \\
\hline 1 & 32,21 \\
2 & 26,22 \\
3 & 20,59 \\
4 & 17,04 \\
5 & 26,46 \\
6 & 27,67 \\
7 & 33,06 \\
\hline
\end{tabular}

Fonte: Elaboração Própria.

A média da resistência à compressão dos corpos de prova que constituem a condição experimental 7 (produzidos sem fibras) foi de 33,06 MPa, valor superior aos compósitos cimentícios que continham fibras, cujo valor de resistência médio variou entre 17,04 MPa a 32,21 MPa. Os maiores valores de resistência à compressão foram obtidos para os compósitos da condição experimental 1, enquanto os menores resultados foram obtidos da condição experimental 4. Pode-se observar pelo Gráfico 1 que o aumento da fração mássica das fibras tende a aumentar a resistência à compressão dos compósitos cimentícios constituídos por fibras finas, entretanto, a resistência à compressão dos compósitos constituídos por fibras grossas diminuiu com o aumento da fração mássica.

Para uma maior confiabilidade dos dados, foram verificados intervalos de confiança de $90 \%$ para os valores de resistência à compressão de cada condição experimental. Os Gráficos 2 e 3 apresentam os intervalos de confiança para os experimentos com fibras grossas e fibras finas, respectivamente.

A Tabela 4 apresenta a média das densidades calculadas para cada condição experimental. Pode-se observar que a densidade dos corpos de prova diminui à medida que a fração mássica das fibras aumenta, visto que, ocorre uma substituição espacial do cimento e da cinza pelas fibras.

Gráfico 1- Valores médios de resistência à compressão.

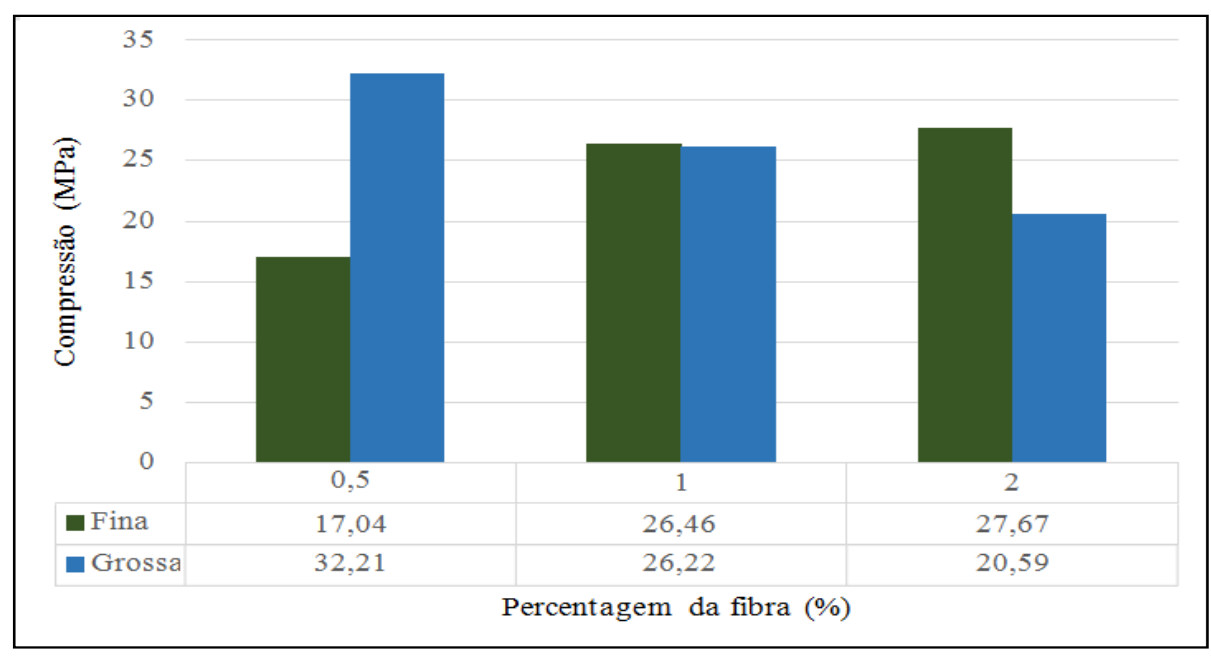

Fonte: Elaboração Própria. 
AMARAL et. al

Gráfico 2- Intervalo de confiança de $90 \%$ para os resultados de resistência à compressão.

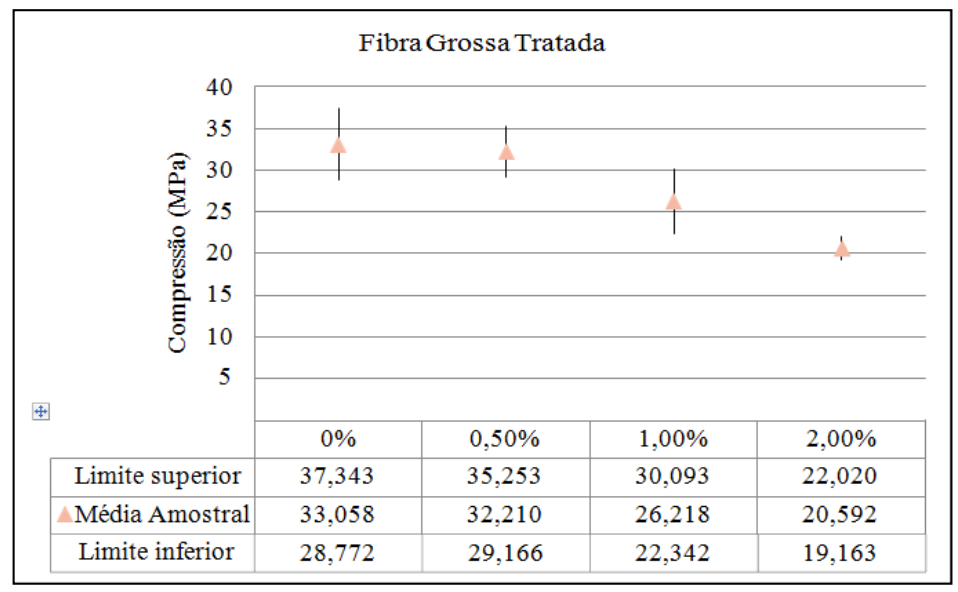

Fonte: Elaboração Própria.

Gráfico 3 - Intervalo de confiança de 90\% para os resultados de resistência à compressão.

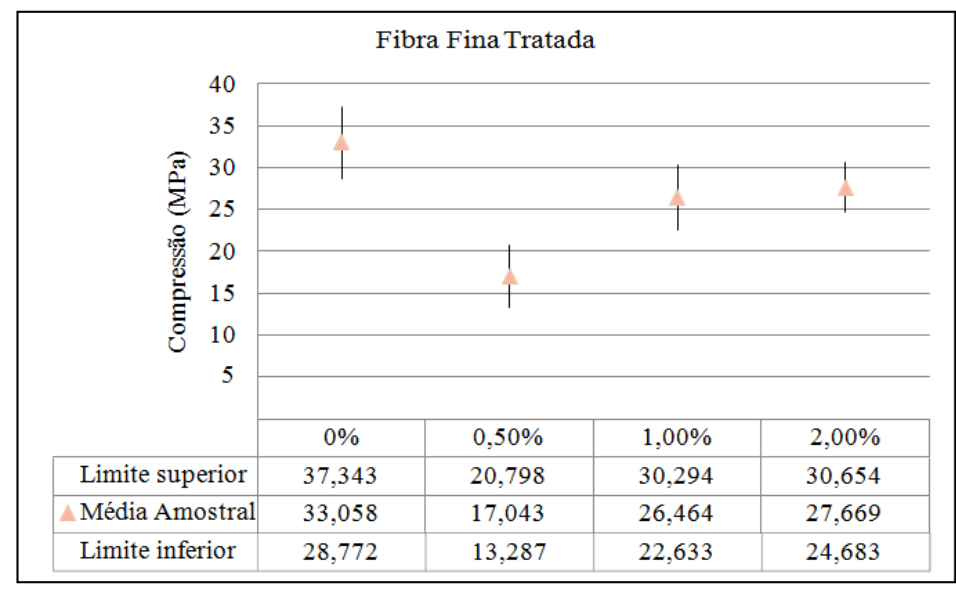

Fonte: Elaboração Própria.

Tabela 4 -Médias das densidades das condições experimentais.

\begin{tabular}{cc}
\hline $\begin{array}{c}\text { Condições } \\
\text { experimental }\end{array}$ & Densidade $\left(\mathbf{g} / \mathbf{c m}^{\mathbf{3}}\right)$ \\
\hline 1 & 1,854 \\
2 & 1,829 \\
3 & 1,819 \\
4 & 1,84 \\
5 & 1,839 \\
6 & 1,816 \\
7 & 1,872 \\
\hline
\end{tabular}

Fonte: Elaboração Própria. 
Indiferente da concentração e da granulometria das fibras utilizadas, percebe-se que a resistência à compressão desse tipo de compósito é inferior ao material constituído apenas de cimento, água e cinza. Isso pode ser explicado devido à diferença de densidade dos materiais que constituem o compósito. Podese afirmar que a fase dispersa atua como pontos vazios dentro do compósito (Figura 5) e, deste modo, quando comparados aos corpos de prova sem fibras fina, os compósitos com bagaço de cana-de-açúcar apresentaram valores menores de resistência mecânica.

Figura 5 - Corpo de prova após ensaio de compressão.

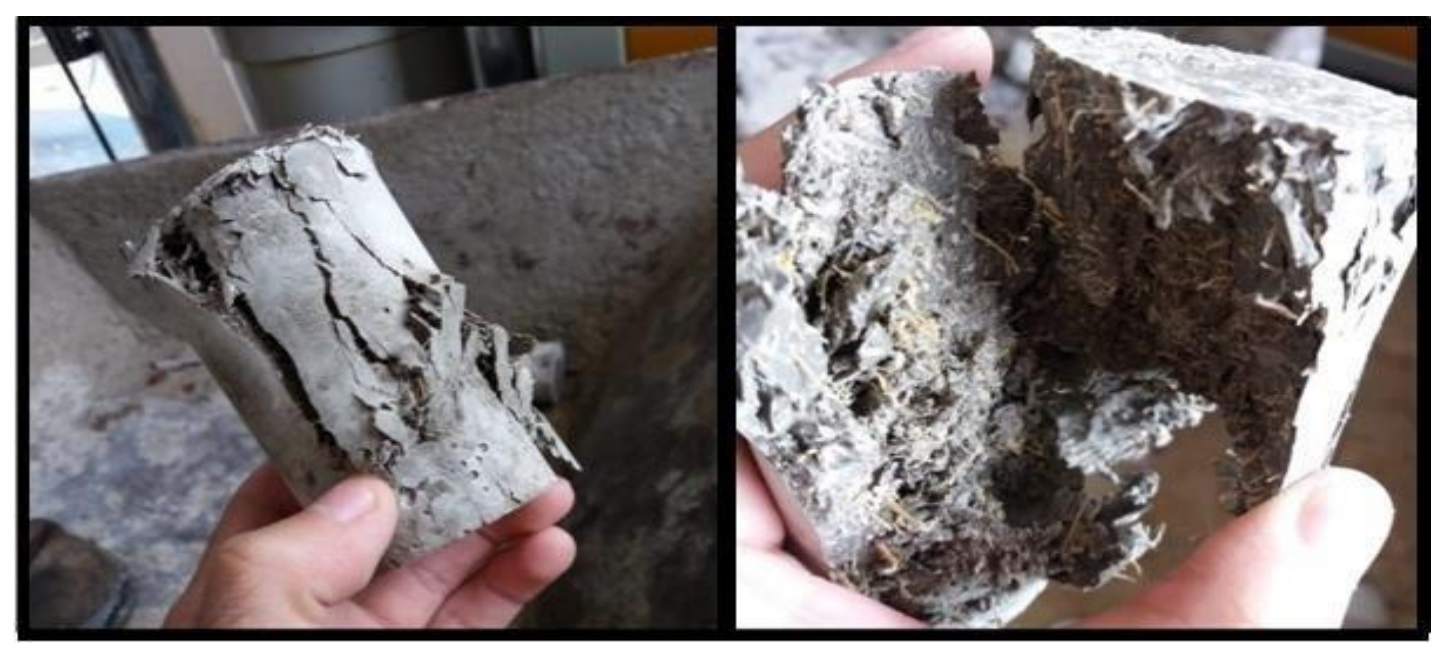

Fonte: Elaboração Própria.

Pelos resultados obtidos, é possível observar que em algumas condições experimentais há uma dispersão maior nos seus respectivos conjuntos de dados do que em outras. Isto pode ser explicado por possíveis erros no processo de fabricação dos corpos de prova ou no processo dos ensaios de compressão. Entretanto, essa variação não influencia nos objetivos deste trabalho.

\section{Conclusão}

Após análise das propriedades mecânicas dos corpos de prova cimentícios confeccionados com bagaço e cinzas da cana-de-açúcar, pôde-se concluir que os melhores resultados de resistência à compressão foram obtidos com o uso das fibras classificadas em faixas granulométricas de abertura US-Tyler 7-20 (grossa) em comparação com fibras de granulometria US-Tyler 40-35 (fina). Apesar de apresentar uma resistência à compressão inferior ao material sem fibras, o uso das fibras pode ser levado em consideração para algumas aplicações, que geram benefícios como: redução da densidade do material, diminuição no uso da pasta cimentícia e a reutilização de tais resíduos agroindustriais, reduzindo assim, o impacto ambiental por eles causado. Para um entendimento mais abrangente sobre compósitos cimentícios, os seguintes estudos são sugeridos: a variação das porcentagens das fibras, a variação da granulometria, ensaios de resistência à tração, ensaio de resistência à flexão, substituição das fibras e cinza no concreto, influência da cinza na pasta cimentícia.

\section{REFERÊNCIAS}

ASSOCIAÇÃO BRASILEIRA DE NORMAS TÉCNICAS. NBR 5738: Concreto - Procedimento para 
moldagem de corpos de prova. Rio de Janeiro, 2015.

ASSOCIAÇÃO BRASILEIRA DE NORMAS TÉCNICAS. NBR 5739: Concreto - Ensaio de compressão de corpos-de-prova cilíndricos. Rio de Janeiro, 1994.

ASSOCIAÇÃO BRASILEIRA DE NORMAS TÉCNICAS. NBR 7215: Cimento Portland - Determinação da resistência à compressão. Rio de Janeiro, 1997.

CALLISTER JR, William D. Ciência e engenharia de materiais: uma introdução. 7. ed. Rio de Janeiro: LTC, 2008.

CONAB. Companhia Nacional de Abastecimento. Boletim de Acompanhamento da Safra Brasileira de Cana-de-Açúcar- $1^{\circ}$ Levantamento Safra 2018/19. Disponível em: https://www.conab.gov.br/info-agro/ safras/cana/boletim-da-safra-de-cana-de-acucar. Acesso em: 30 jul.2018.

HELENE, Paulo; ANDRADE, Tibério. Concreto de Cimento Portland. In: ISAIA, Geraldo Cechella. Materiais de Construção Civil e Princípios de Ciência e Engenharia de Materiais. IBRACON, 2010. Disponível em: https://www.researchgate.net/profile/Paulo_Helene/publication/266487937_Concreto_de_Cimento_Portland/links/55d47f5608aec1b042a137ff.pdf. Acesso em: 25 nov. 2018.

LIMA, Caio Ivson Vasconcelos et al. Concreto e suas inovações. Ciências exatas e tecnológicas, Maceió, v.1, n.1, p. 31-40, maio. 2014. Disponível em: https://periodicos.set.edu.br/index.php/fitsexatas/article/ view/1285/755. Acesso em: 24 nov. 2018.

MACEDO, Pamela Camargo. Avaliação do desempenho de argamassas com adição de cinza do bagaço de cana-de-açúcar. 2009. 116 f. Dissertação (Mestrado) - Universidade Estadual Paulista, Faculdade de Engenharia de Ilha Solteira, 2009. Disponível em: http://hdl.handle.net/11449/91450. Acesso em: 24 nov. 2018.

VIEIRA, G. L. L.; MARTUSCELLI, C. C.; CASTANON, U. N.; RODRIGUES, V.; CARDOSO, A. M. ; NONATO, Y. . Estudo das Propriedades Físicas e Mecânicas e da Degradação de Compósitos Cimentícios com Fibras Naturais. In: CONGRESSO LUSO BRASILEIRO DE MATERIAIS DE CONSTRUÇÃO SUSTENTÁVEIS. 2. Anais... João Pessoa, 2016.

ZARDO, A. M.; BEZERRA, E.M.; MARTELLO, L. S.; JUNIOR, H. S.. Utilização da cinza de bagaço canade-açúcar como "filler" em compostos de fibrocimento. In: CONFERÊNCIA LATINO-AMERICANA DE CONSTRUÇÃO SUSTENTÁVEL,1. Anais... SÃO PAULO, 2004. 